\title{
Representação e Poder: A Mulher Que Falou Através de Apolo NAS HistóRIAS DE HERódoto
}

\author{
Isabela Casellato Torres $^{1}$
}

\section{RESUMO}

A obra Histórias, produzida no século V a.C. por Heródoto de Halicarnasso, é o único escrito do chamado "Pai da História" que chegou até a contemporaneidade. $\mathrm{O}$ autor viveu em torno de 480 até aproximadamente 425 a.C. Em Histórias, aborda muito além das Guerras Greco-Pérsicas, cujo relato é o mais substancial na posteridade. Heródoto descreve, dentro deste contexto, as representações de atuações de mulheres gregas e persas como conselheiras de assuntos bélicos junto aos seus maridos e/ou demais personagens masculinos próximos. Nesse sentido, temos como hipótese que o autor grego coloca mulheres gregas e persas no mesmo patamar de atuação: de mantenedoras da ordem político-social. Analisaremos como a historiografia atual compreendeu o lugar do feminino na obra de Heródoto, dialogando com estudo de caso presente no documento, nesse artigo, a profetisa Pítia.

PALAVRAS-CHAVE

História de gênero; Conflitos bélicos; Heródoto.

\footnotetext{
${ }^{1}$ Mestranda CAPES no programa de pós-graduação na Faculdade de Ciências Humanas e Sociais/UNESP Campus Franca - SP, orientada pela Profa. Dra. Margarida Maria de Carvalho. E-mail: isa_casellato@hotmail.com.
} 
Mare Nostrum, ano 2020, v. 11, n. 1 .

\section{Introdução}

Os estudos sobre Heródoto, nomeado por Cícero como o "Pai da História", englobam diversos campos de estudos. O autor, que nasceu por volta de 480-485 a.C. e morreu por volta de 420 a.C, discorre sobre diversos povos e costumes que viu e ouviu ${ }^{2}$ durante suas viagens. A obra Histórias, composta no século V a.C, é a única obra do autor que chegou até a contemporaneidade e foi dividida em nove livros. O presente artigo é parte de uma investigação mais abrangente em andamento de minha dissertação de mestrado, na qual oito dos nove livros da obra Histórias são discutidos para analisar a representação das mulheres gregas e persas que atuaram como conselheiras bélicas nas Guerras Greco-Persas.

Duas questões norteiam a discussão que pretendemos aqui desenvolver: a primeira, relaciona-se a uma questão historiográfica—por que a historiografia recente privilegiou outros documentos antigos, que não Heródoto, para compreender as relações que se estabeleceram e pensar um perfil de mulher grega no século V a.C.? Para além de trezentas e setenta e cinco citações de mulheres que atuam de alguma maneira em Histórias (Dewald, 1981) temos diversas situações em que podemos visualizar como a sociedade grega organizava-se. Mesmo assim, há bem mais citações de Eurípides, Aristófanes, Xenofonte, Aristóteles, Homero, mas raramente vemos Heródoto inserido nessa historiografia para fazer um panorama sobre as relações e condições da mulher na Grécia Antiga no século V a.C. Em alguns trabalhos, Heródoto até aparece, mas sua obra não é priorizada em relação aos demais autores.

A segunda questão, relaciona-se a um estudo de caso da fonte a fim de discutir a importância conferida à mulher e sua atuação como conselheira em Histórias. Analisaremos o caso da profetisa Pítia, responsável por transmitir as palavras de Apolo no oráculo de Delfos. De acordo com Carolyn Dewald (1981, p. 113), se considerássemos a quantidade de vezes que uma mesma mulher é citada em Histórias, Pítia seria a mais importante dentre elas, pois é citada em todos os livros, com exceção do segundo (quarenta e cinco ocasiões aconselhando reis, tiranos, aristocratas e o povo tanto grego como bárbaro). Neste ponto, trataremos também da figura da mulher e sua relação com o poder: tanto as mulheres persas como as gregas com diferentes status sociais relacionam-se, influenciam e aconselham homens, muitos deles, seus maridos

2 Para saber mais sobre a discussão do ver e ouvir no discurso herodotiano: Hartog (2014). 
que são reis ou agentes oficiais da pólis ou da Pérsia. Questionamos por que Heródoto evidencia as mulheres na posição de aconselhar homens e como isso pode ser identificado em sua obra.

\section{As relações de gênero em Heródoto: debates historiográficos}

Desde o século XIX há estudos sobre a presença da mulher na Antiguidade, mais precisamente, as mulheres gregas. Essas investigações eram, principalmente, sobre o status social que elas ocupavam em Atenas, tendo sido caracterizadas como submissas e sem acesso à educação e à política. Esse tipo de perspectiva foi generalizado para as mulheres gregas de outras regiões. A partir da década de 1960, com a segunda onda feminista, o lugar da mulher na história é questionado pela história social das mulheres; os documentos começam a ser analisados como produções masculinas que dizem respeito às mulheres. No entanto, é somente com os estudos de gênero, desenvolvido nos fins dos anos 1980 do mesmo século, que se tentará compreender as identidades, as perspectivas sociais e culturais que constituem o gênero, afastando-se da concepção que focava apenas nas diferenças sexuais biológicas. Pedro Paulo de Abreu Funari (2003, pp. 299-310) afirma que pesquisar e escrever sobre gênero não significa o mesmo que traçar uma história das mulheres. Enquanto o gênero investiga as identidades que se relacionam e, assim, constituem-se, a história das mulheres não abrange o relacional e destaca o biológico, que pouco engloba o contexto cultural em que os indivíduos estão inseridos para compreender a constituição de uma identidade feminina ou masculina.

De acordo com Scott (2011, p. 89), muitos desses estudos sobre gênero se basearam nas análises sociológicas e nos estudos do pós-estruturalismo; observando os papéis que eram designados às mulheres e aos homens ao longo da história, enfatizavam que só é possível estudar mulheres se elas forem definidas em relação aos homens, da mesma maneira, que, para estudar os homens, é necessário diferenciá-los das mulheres. Ademais, "uma vez que o gênero foi definido como relativo ao contexto social e cultural, foi possível pensar em termos de diferentes sistemas de gênero e nas relações com outras categorias”, como status social, etnia e poder (Scott, 2011, p. 89).

Leanna Goodwater, em seu livro Women in Antiquity: an annotated Bibliography (1975), faz um levantamento dos trabalhos do início do século XX até os anos de 1970 
sobre mulheres na Grécia Antiga, analisando qual foi o lugar que o feminino ocupou nos documentos do século $\mathrm{V}$ a.C. Heródoto é citado no texto apenas uma vez, e não identificamos nenhuma crítica significativa sobre nosso autor. Quando é mencionado, não há uma discussão aprofundada sobre como a mulher foi tratada por Heródoto, há apenas uma citação de que em sua obra encontramos exemplos de mulheres atuando.

Sarah Pomeroy (1973), quando diferencia a mulher representada na tragédia e a mulher que considera como uma representação mais próxima da mulher ateniense clássica, cita Homero, Eurípedes, Sófocles, Ésquilo e Aristófanes, para fazer aproximações e diferenciações. No entanto, notamos que Heródoto é mencionado com ressalvas por parte da autora, pois ela defende que o feminino aparece em casos isolados na obra do autor. Observamos esse "fenômeno da exclusão de Heródoto" também em autoras como Claude Mossé (1990), Sue Blundell (1995), Nicole Louraux (1997).

Josine Block propõe uma possível explicação para esse fato, comparando Histórias com A História da Guerra do Peloponeso, de Tucídides. Se em Histórias, como já dito, há trezentas e setenta e cinco referências de mulheres, em Tucídides há apenas seis. De acordo com Block, a concepção de história que este último autor produz não espera que mulheres possam ser agentes históricos (2002, p. 226). Nessa perspectiva, a autora diz que Tucídides defende, portanto, um oikos vulnerável no estado de guerra. Ou seja, a função social que, normalmente, era atribuída à mulherprover e proteger o lar-é entendida como fragilizada no momento da guerra.

Nos últimos quarenta anos, sistematizamos menos de dez trabalhos na historiografia inglesa, americana, brasileira e portuguesa ${ }^{3}$ que abordam as relações de gênero em Heródoto e tentam compreender a função da mulher e do feminino na sociedade grega. Dentre as pesquisas mais citadas, temos: Carolyn Dewald, que analisou as mulheres de Heródoto nos anos de 1980; Rosaria Vignolo Munson, também na década de 1980, que fez essa inclusão focando em casos de mulheres específicas; Josine Block, no início do século XXI, fez uma análise da presença e participação das mulheres em Histórias; Yance Hugges Dominick, em 2007, analisa uma rainha persa e sua influência na obra herodotiana; Nathalia Monseff Junqueira, em 2011, contrasta a presença das mulheres nos vasos áticos com a documentação de Heródoto; e Lynett

\footnotetext{
${ }^{3}$ Destacamos tais historiografias pois se enquadram nas línguas que temos acesso. Vale ressaltar que, por vezes, encontramos autores que trabalham com alguma mulher específica de Heródoto, mas notamos que não há uma sistematização dessas mulheres, com exceção do artigo da historiadora Carolyn Dwald (1981).
} 
Mitchell, que, embora não trabalhe especificamente com Heródoto, recentemente o incluiu com problematizações na análise de mulheres que estão inseridas em contextos de guerra e paz ${ }^{4}$.

Acreditamos que há muito a explorar em Heródoto para compreender as relações que se forjaram nas sociedades e entender alguns papéis que as gregas e as persas tiveram durante os séculos VI e V a.C. Para expor porque esta historiografia é insuficiente, discutiremos como o feminino e o masculino foram abordados pelos autores citados e mostraremos, através da fonte, o que ainda precisa ser estudado em Heródoto.

Consoante com a concepção de História Social das Mulheres, Loraux (1997, p. 4) discute como o binário feminino/masculino pode ser compreendido nas fontes documentais do século $\mathrm{V}$ a.C. A autora acredita que o feminino deve ser discutido como um operador que nos permite pensar a identidade como virtualmente construída pelo outro. Além disso, quando se fala em homem grego ou quando se lê homens gregos, deve-se compreender essa operação de pensamentos e identidade bem mais complexa do que um simples quadro representativo de categorias antitéticas. Embora tais considerações sejam importantes, nosso trabalho se afasta de seu estudo no momento que Loraux propõe que há uma diferença dos sexos nítida nos documentos e que essa diferença é normalmente percebida com um entendimento negativo do lugar feminino, formando uma concepção positiva do masculino como dominante. Tal consideração deriva, principalmente, dos poemas de Hesíodo, que contam o surgimento da condição humana em meio ao mundo que era apenas dos deuses imortais.

De acordo com Marta Mega de Andrade, nos poemas Teogonia e Os Tabalhos e os Dias, onde é narrado o mito de Prometeu e Pandora, surge o conceito de "tribo dos homens" (phûl' antrópōn) e a partir de armadilhas que Prometeu oculta dos deuses é criado um "incombatível ardil: um mal oculto sob a aparência sedutora de um bem" (2001, pp. 41-45), Pandora, representando a "raça das mulheres" (génos gynaikôn). Em Os Trabalhos e os Dias, há outro desdobramento da fabricação da mulher. Neste, Pandora é caracterizada pelos "dons" que formam a mulher, portanto, tem-se a concepção do feminino. Pandora representa no feminino uma "múltipla armadilha, da múltipla prisão: trabalho, fome, doenças, mortalidade, imprevidência” (2001, p. 47); por

\footnotetext{
${ }^{4}$ Todas as obras estão referenciadas na bibliografia deste artigo.
} 
Mare Nostrum, ano 2020, v. 11, n. 1 .

conseguinte, equivale, na dicotomia feminino/masculino, ao polo negativo. $\mathrm{O}$ homem, por outro lado, apresenta-se como polo positivo, articulando-se e opondo-se ao feminino. Essa interpretação do feminino e masculino permeia a mentalidade de diversos autores antigos dos séculos V e VI a.C., porém no desenvolver do nosso trabalho mostraremos porque acreditamos que Heródoto afasta-se dessa interpretação.

Ao discutir o feminino e sua representação em Heródoto, Tucídides e Xenofonte, Loraux aponta que o papel do feminino, quando presente na guerra, limita-se aos momentos de crise, momentos em que qualquer anomalia ${ }^{5}$ poderia intervir modificando as regras e valores da sociedade. Este papel feminino seria representado pelos antigos sempre para atacar a virilidade do homem e a natureza feminina, que, no contexto de guerra, poderia ser vislumbrada em termos de excesso, ousadia e tomada por impulsos. Principalmente quando envolvida em uma ação coletiva, o feminino seria caracterizado por uma desintegração das individualidades no momento que nele se envolve. Contrapondo-se à ação do homem vista em um coletivo como escolha espontânea, o feminino estaria imbuído de coragem para um fim — tal afirmação explicaria a "imitação do feminino em um mundo que é dos homens” (Loraux, 1997, pp. 246-247).

Analisando, por exemplo, o caso em que as mulheres atenienses se unem para adquirir informações sobre seus maridos que não retornaram da guerra contra os argivos e eginetas, vemos uma união, mesmo que esta acabe com vingança e punição às mulheres:

Mesmo esse único homem, segundo se diz, não sobreviveu por muito tempo e teria perecido da seguinte maneira: de volta a Atenas ele anunciou o desastre; em face daquela notícia as mulheres cujos maridos haviam partido para Árgina, indignadas por ele ter sido o único a salvar-se entre tantos, cercaram o infeliz por todos os lados e o cortaram com os pinos dos broches de seus vestidos, cada uma perguntando-lhe onde estava seu marido. Ele morreu assim, e os atenienses consideraram o crime de suas mulheres um fato ainda mais terrível que o seu desastre. Sem saber qual o castigo a infligir a essas mulheres, eles mudaram os

\footnotetext{
${ }^{5}$ Atentamos para o fato de o termo ser utilizado pela autora (Loraux, 1997).
} 
trajes que elas costumavam vestir por outros iguais aos usados na Iônia. (Hdt. V.87)

A passagem supra é interpretada por Lynett Mitchell. A historiadora argumenta que sobreviver a uma batalha era quase uma traição para as mães daqueles que estavam mortos. Essa história das mulheres atenienses representava, portanto, o sentimento da comunidade (Mitchell, 2020, pp.7-8). A história representa uma reação exagerada, pelo menos na medida em que reconhece que os feitos subsequentes das esposas foram piores do que a derrota da guerra contra os argivos e eginetas. Ou seja, se contrapormos a visão de Loraux e Mitchell, compreendemos que as mulheres se unem por um sentimento relacionado aos valores daquela sociedade ${ }^{6}$ e que o exagero contribui para exemplificar sua importância e não necessariamente mostra que as mulheres eram desintegradas das suas individualidades ou tomadas por impulsos.

Mitchell exemplifica diversas mulheres representadas individualmente ou coletivamente no âmbito de guerras. Mostra-nos que geralmente é dado como certo que, tirando algumas mulheres míticas como as Amazonas, as mulheres não participavam ativamente da guerra, pelo menos não como guerreiros regulares. Porém, segundo a autora, sabe-se que as mulheres participavam da defesa de suas cidades e casas, além de estarem preparadas caso houvesse a necessidade de assumir um papel de liderança em batalhas, principalmente se seus maridos ou filhos estivessem ausentes. Como vemos, por exemplo, no livro VII de Heródoto com a personagem Artemísia:

Não farei menção aos outros oficiais, pois isso não é necessário; mencionarei, porém, Artemísia, porquanto me causa profunda admiração o fato de essa mulher haver participado da expedição contra os helenos. Com efeito, após a morte de seu marido, embora tivesse um filho de tenra idade ela mesma passou a exercer a tirania, e obedecendo à sua coragem e à sua audácia viril incorporou-se à expedição sem ter sido compelida a isso de forma alguma. (Hdt. VII.99)

\footnotetext{
${ }^{6}$ Neste caso, podemos considerar os valores da sociedade como a coragem e a traição à honra, já que apenas um homem sobreviveu à guerra e não trouxe seus companheiros de batalha vivo.
} 
Mare Nostrum, ano 2020, v. 11, n. 1 .

A partir do excerto, Ana Lúcia Amaral (1994, p. 30) argumenta que a personagem impõe-se, não pelos habituais atributos femininos, como por exemplo, a beleza, e, sim, pelas vestes do poder soberano assumido após a morte do marido. Outro aspecto destacado por Rosaria Vignolo Munson (1988, p. 94) é que talvez Heródoto não tenha considerado necessário nomear os líderes do exército de Xerxes porque eles seguiam a expedição sem autoridade, apenas como meros escravos, como outros soldados. Porém, quando fala de Artemísia, ele a descreve como "obedecendo à sua coragem e à sua audácia viril incorporou-se à expedição sem ter sido compelida a isso de forma alguma" (Hdt. VII.99). Mitchell adiciona que mesmo que coragem fosse viril e, portanto, um adjetivo masculino, essa era uma virtude cara por toda a comunidade grega, tanto pelos homens quanto pelas mulheres. Era como se a coragem de seus homens e mulheres fosse compartilhada na glória grega $(2019, \text { p. } 4)^{7}$.

Através de outra menção da participação de Artemísia em Histórias no livro VIII, Amélie Kurth nos evidencia uma mescla de valores presentes em Heródoto. Quando Xerxes, rei persa, observa o sucesso da comandante durante a batalha, é relatado que o rei faz o seguinte comentário: "Meus homens se transformaram em mulheres e minhas mulheres em homens" (Hdt. VIII.88). A anedota contrasta com a ênfase positiva relacionada à Artemísia e, segundo Kurth (2001, pp. 1-5), demonstra uma crítica grega sobre os persas para desdenhar o inimigo derrotado: o fracasso persa na guerra estaria relacionado aos seus homens serem tão efeminados que a mais corajosa entre eles era uma mulher.

Mesmo reconhecendo que nesta passagem de Artemísia Heródoto talvez esteja imbuído do ideal de mélissa - a mulher-abelha seria a boa esposa, zelosa aos bens do oikos, silenciosa e subserviente (Mega, 2003)—, o que justificaria o autor grego conceber a mulher como simbologia da fraqueza, não acreditamos que o autor represente o feminino somente ligado a características negativas. Em que pese a originalidade do trabalho de Nathalia Monseff Junqueira, discordamos da autora, que, ao contrastar a cerâmica ática dos séculos VI e V a.C. com o relato de Heródoto, supõe que o modelo da mulher-abelha está mais presente no relato herodotiano do que nas cerâmicas (Junqueira, 2011, p. 11). Não desconsideramos o uso do modelo de mélissa, já que as Histórias não podem ser retiradas de seu contexto histórico; mas há, sim, uma

\footnotetext{
7 Texto adquirido diretamente com a autora em sua palestra ministrada no Museu de Arqueologia e Etnologia da Universidade de São Paulo, em 12 de abril de 2019.
} 
contradição ao modelo. A própria Artemísia nos mostra essa contradição nos capítulos 101 e 102 do livro VIII, quando Xerxes pede que a chamem e solicita conselhos sobre como deveria agir perante as solicitações de Mardônio, comandante persa, para negociações com os gregos após a batalha de Salamina. Ou seja, além de possuir destaque na descrição de tropas durante a Guerra, Heródoto representa Artemísia como conselheira de um rei.

Vislumbramos mais exemplos de mulheres sendo representadas como agentes ativos e aconselhando seus maridos ou personagens masculinos. Como, por exemplo, no livro III temos a filha do soberano de Corinto, que é mandada para conversar com o irmão para tentar convencê-lo a voltar para Corinto para seguir governando a pólis. $\mathrm{O}$ irmão estava revoltoso com o pai por ele ter matado sua mãe, e a filha era a esperança para persuadir o rapaz:

E Periandro, pressionado pelo jovem, enviou-lhe, pela segunda vez, uma mensagem pela sua própria irmã, que era sua filha, pensando que ele seria mais convencido por ela. Depois de ela ter chegado, disse: “-Ó menino, deseja mais que a tirania caia nas mãos de estranhos e a casa de nosso pai seja saqueada que tu mesmo retornes para tomar posse de seus bens? Retorna para o nosso palácio, para de punir-te com esta pena. A obstinação é uma aquisição funesta; não cures o mal com o mal. Muitos preferem a equidade à justiça. Muitos já abandonaram as coisas paternas por procurarem as maternas. A tirania é uma coisa incerta, muitos são os amantes dela, mas nosso pai já está envelhecendo e com a idade avançada; não dês os teus próprios bens a estranhos. (Hdt. III.53)

Prosseguindo o debate historiográfico, Kuhrt, ao escrever sobre mulheres que se envolvem em conflitos no Antigo Oriente Próximo, afirma que a guerra, mais do que qualquer outra atividade social, é uma boa circunstância para definir, classificar e sustentar os papéis tradicionais de gênero. Assim, uma das principais razões pelas quais as mulheres, muitas vezes, estão na periferia da historiografia diz respeito ao fato de não serem combatentes. Da mesma maneira, na Antiguidade, quando as mulheres aparecem como líderes de guerra ou combatentes, são analisadas como uma aberração, uma 
peculiaridade. Kuhrt expõe que, normalmente, na concepção clássica grega, a luta é algo que as mulheres bárbaras fazem, sendo uma atividade que classifica essas sociedades como "não civilizadas" (2001, pp. 3-4).

Entretanto, no caso já exposto de Artemísia, que é de origem Cária, governante e comandante de Halicarnasso, participando da guerra Greco-Pérsica como aliada dos persas, não visualizamos uma descrição de aberração ou "não civilizada". Ao fazer sua descrição, compreendemos que Heródoto dá especial atenção a esta mulher, talvez porque, além de suas participações, a esposa-guerreira seja da mesma pólis que o autor, a saber, Halicarnasso. Acrescentamos que a vasta menção sobre a guerreira proporciona diferentes interpretações, mas que em sua grande maioria, caracterizamos como positiva.

Mitchell aponta ainda que "embora nossas fontes literárias (escritas por homens) não forneçam muitos exemplos de mulheres trabalhando ativamente pela paz ou envolvidas em negociações de paz, existem algumas que são ainda mais surpreendentes e notáveis porque elas existem" (2019, p. 15). Vemos em Heródoto a personagem Atossa interferindo em assuntos bélicos do seu marido, rei persa, para ajudar um médico grego que a curou de um tumor nos seios e precisava de uma maneira para voltar à Grécia:

“Olhe”, disse Atossa, "deixe os Cítas para o presente; você pode tê-los quando quiser. Eu digo a você, marche contra Hélade ${ }^{8}$. Eu ouvi falar sobre as Lacônias, as Argivas, Áticas e Coríntias e gostaria de tê-las como servas”. Dário respondeu: "Mulher, já que você acredita que devemos tentar invadir a Grécia, primeiro parece-me melhor enviar espiões persas com o homem que você mencionou que poderá nos dizer tudo o que aprenderam e observaram; e então, quando eu estiver plenamente informado eu me levantarei contra eles.” (Hdt. III.134)

Como vimos no excerto retirado do livro III de Histórias, Atossa é apresentada como aquela que tem o poder de influenciar seu marido através de sugestões e

\footnotetext{
${ }^{8} \mathrm{O}$ termo Hélade mencionado por Heródoto refere-se ao território que os helenos ocupavam, ou seja, o que chamamos de Grécia e gregos.
} 
conselhos. Yancy Hughes Dominick expõe esse poder da mulher de Dario como o de uma agente que mudou o curso da história. Porém, apesar de visualizar Atossa como uma mulher que possuía poder de persuasão e capacidade de tomada de decisões, Dominick questiona a real influência de Atossa e pergunta se ela agiria de tal maneira se não tivesse sido instruída pelo médico grego que a curou do tumor nos seios (2007, pp. 432-444). O médico era prisioneiro de Dario e via no ataque à Grécia uma maneira para retornar ao seu local de origem.

Dominick, diferentemente do que estamos propondo, acredita que Heródoto trata as mulheres, mesmo nos momentos que possuem papéis importantes, mais como um instrumento de fala para chegar-se a um objetivo do que agentes propriamente ditos. No entanto, pensamos que a partir do momento que uma mulher está falando a um homem o que deveria ser feito, essa ação já é cabível de ser pensada como pertencente a um agente ativo, principalmente se lembrarmos que este não é um lugar considerado feminino na Antiguidade.

Nesse sentido, temos como uma das hipóteses que o autor grego insere mulheres gregas e persas no mesmo patamar de atuação: de mantenedoras da ordem políticosocial. Embora a historiadora Bárbara Alexandre Aniceto se debruce sobre outra documentação, a saber, aristofânica, compartilhamos da noção de mantenedora por ela defendida de que "as mulheres seriam portadoras das soluções políticas, porque postas em situações emergenciais e conflituosas da pólis" (2017, pp. 18-19). Em momentos de crises, em que homens não sabem como agir, as mulheres apresentam soluções e conselhos que mantêm a ordem da sociedade tanto no âmbito da política quanto no âmbito social. Para além dos exemplos já mencionados, podemos vislumbrar a atividade no livro VII com Gorgo, uma espartana, esposa do general espartano Leônidas:

Os lacedaemonianos foram os primeiros a serem informados de que o rei estava se preparando para atacar a Hélade; [...] Demáratos, filho de Aríston, exilado entre os $\operatorname{medos}^{9}$, não era, como eu suponho (a razão é também minha aliada), amigo dos lacedemônios, e deixo imaginar se o que ele fez foi feito por boa vontade ou triunfo rancoroso. Quando Xerxes foi decidido a marchar contra Hélade,

\footnotetext{
${ }^{9} \mathrm{O}$ termo medos é utilizado por Heródoto quando se refere ao povo do Império Medo do qual, para o autor grego, os persas são descendentes. Por vezes, Heródoto utiliza o termo como sinônimo para falar sobre os persas.
} 
Mare Nostrum, ano 2020, v. 11, n. 1 .

Demáratos, que estava então em Susa e tinha conhecimento disso, desejou enviar uma mensagem aos lacedemônios. Ele, no entanto, temia ser descoberto e não tinha outra maneira de informá-los além desse truque. [...] Quando a plaqueta chegou a Lacedemônia, os lacedemônios não conseguiram adivinhar seu significado, até que finalmente (como me disseram) Gorgo, filha de Cleomenes e esposa de Leônidas, descobriu sozinha o truque e aconselhou-os a raspar a cera para que eles encontrassem a escrita na madeira. Quando o fizeram, encontraram e leram a mensagem, e prontamente a enviaram ao restante dos gregos. Esta é a história como é contada. (Hdt. VII.239)

A partir do excerto citado, consideramos Gorgo e o conjunto de mulheres selecionadas por nós não apenas como disseminadoras de informações, mas também como agentes políticos não oficiais, visto que elas se relacionam com generais e governantes. Além disso, acreditamos que, independente da proveniência dessas mulheres, assim como seu status - esposas legítimas, uma escrava, esposas espartanas, uma guerreira, filhas de reis e esposas de reis persas-, o autor as retrata como um veículo de alerta de conflitos que ocorrem nas póleis gregas e na Pérsia. Como são descritas influenciando em conflitos, essas mulheres alertariam como proceder ou agir; portanto, compreendemo-las como um instrumento para alertar conflitos.

Percebemos representações da mulher junto ao homem, interagindo para alcançar um fim ou auxiliando durante tomadas de decisões. Portanto, nossa pesquisa enquadrase dentro de uma perspectiva de gênero em que o feminino é analisado juntamente com o papel masculino e interpretado através dos contextos sociais e políticos de ambos. É possível elencar em níveis o porquê de analisar nossa pesquisa através dos estudos de gênero, quais sejam: ao lugar que Heródoto insere as mulheres gregas e as persas agindo - como conselheiras ou influentes em contextos bélicos-, um lugar que é tido como masculino; e estando inseridas nesse local de representação, elas ainda se dirigem aos homens com soluções e estratégias de guerra; a perspectiva de gênero como instrumento analítico nos auxilia ainda para assimilarmos os papéis possíveis de serem exercidos pelas mulheres e homens, afastando-os do biológico e interpretando o que caracteriza um indivíduo masculino e outro feminino na época estudada. 
Através dos exemplos e da historiografia exposta, visualizamos que Heródoto contribui para compreendermos os valores caros àquela sociedade de maneira menos sistematizada — a mulher representando algo negativo e o homem algo positivo-e mais relacional e dinâmica. A presença da mulher na obra Histórias, novamente segundo Dewald, não é para provar uma tese de como elas são ou não atores sociais; elas tendem a ocorrer incidentalmente, ou seja, não são inseridas de maneira forçada, mas aparecem como uma parte constitutiva da sociedade (1981, p. 115). Tal ideia reforça nossa hipótese de que é possível trabalhar as relações de gênero em Heródoto, visto que as mulheres casadas surgem como partícipes naturais nas sociedades na qual estão inseridas. Por esse motivo, tal retrato revela aspectos do comportamento feminino e valores sociais que historiografia da década de 1970 até a contemporaneidade, muitas vezes, negligenciam.

\section{Pítia: a mulher que falou através de Apolo em Delfos}

A adivinhação possuiu um lugar de destaque na história do mundo antigo Grego. O sistema de crenças funcionava concomitantemente com os oráculos. Segundo Herbert William Park e Donald Ernest Wilson Wormell (1956), um dos motivos do oráculo de Delfos ser tão importante relacionava-se à sua localização: a tradição grega dizia que Zeus queria definir o ponto exato do centro da Terra e Delfos ocupava, nos mapas gregos, este lugar. A cidade tornou-se também por muito tempo o centro espiritual do mundo Helênico. Desde pessoas comuns até embaixadores oficiais, todos iam consultar o oráculo para obter respostas sobre o que deviam ou não fazer ${ }^{10}$.

Dito isto, interessa-nos compreender como a mulher ocupando um papel de extrema relevância para uma sociedade foi vista pelos seus similares, pois, mesmo que transmitindo as palavras de um deus, ela permanecia sendo uma mulher. Concordamos com o argumento de Susana Maria Marques Carrilho, no que concerne à análise da sacerdotisa: mais do que interpretar as mensagens que a Pítia proferia, interessam-nos "os aspectos de reconhecimento social que esta mulher adquiria graças à condição sagrada inerente ao seu estatuto de intérprete divina" (2013, p. 72) e ainda como, a

\footnotetext{
${ }^{10}$ Uma historiografia mais recente diz que, na verdade, poucos gregos estavam em posição de consultar o oráculo de Delfos, já que qualquer consulta necessitava ser bem planeja e somente aqueles que possuíam um status social mais elevado teria condições de compreender o que era transmitido nas procissões em versículos. Para saber mais ver: Flower (2008).
} 
Mare Nostrum, ano 2020, v. 11, n. 1 .

partir dessa posição, suas mensagens tidas como verdades influenciaram nas Guerras Greco-Pérsicas.

Quem foi essa mulher que transmitia as palavras de Apolo e que é citada quarenta e cinco vezes na obra de Heródoto? Poucos autores do período clássico grego escreveram detalhes sobre a vida de Pítia e, de acordo com o historiador Michael Flower, o que se sabe deriva de fontes tardias (2008, pp. 211-216). Através de Diodoro (XVI.26, 6), sabe-se que Pítia era uma jovem virgem, uma exigência para ser profetisa no oráculo. É dito que tal convenção foi alterada após Pítia ser abusada por um investigador. Permite-se, então, que uma mulher de por volta de cinquenta anos se vista como virgem para permanecer profetizando. Plutarco reafirma a informação sobre a sacerdotisa ser uma mulher de cinquenta anos e que, mesmo casada anteriormente, naquele tempo permanecia casta. Conforme Plutarco ainda, a profetisa de Delfos teria vindo de uma família simples e não teve uma educação especializada-uma corrente historiográfica ${ }^{11}$ debate que isso é bem improvável, dificilmente uma mulher sem instrução conseguiria fazer versículos em hexâmetros, já que esta não era uma fala próxima à que era usada pelo povo grego no dia a dia. Vemos no trecho abaixo que, para além da métrica, há a o enigmático que também se faz presente:

Mas quando um mulo torna-se rei dos medos,

então, lídio, de pés delicados, pela margem do Hermo

coberta de pedrinhas, fuja e não esperes,

nem te envergonhes por seres um covarde. (Hdt. I.55)

A passagem citada pertence ao livro I de Heródoto, em um dos diversos momentos em que a sacerdotisa Pítia profere o oráculo de Delfos para Creso, rei Lídio. Nessa passagem, temos a resposta de Pítia sobre se a monarquia Lídia seria duradoura, um complemento à pergunta feita sobre se o povo lídio deveria fazer uma expedição militar contra os persas. O oráculo de Delfos tornou-se, na Antiguidade Clássica, um dos mais famosos por conta da sua confiabilidade na transmissão de mensagens. Mesmo

\footnotetext{
${ }^{11}$ Para mais informações ver: Flower (2008); Bowden (2005); Fontenrose (1978).
} 
no caso dessa passagem, em que há uma interpretação errônea por parte do rei Lídio sobre entrar em conflito com os persas, a mensagem de Pítia não é descredibilizada; o que é questionado é a interpretação de quem recebeu a mensagem, e não o oráculo.

Há, em Histórias, apenas duas vezes em que a conduta de Pítia é questionada. A primeira está presente no livro $\mathrm{V}$, quando os Alcmeónidas subornam a profetisa para que todas as vezes em que os espartanos consultassem o oráculo sua resposta fosse favorável a Atenas. Nesse caso, Heródoto parece não acreditar totalmente na informação e não emite sua opinião explicitamente sobre o assunto-afirmamos isto a partir da expressão do autor "Então, segundo se conta em Atenas..." (Hdt. V.63). O segundo caso está presente no livro VI e diz respeito à legitimidade de Demáratos, rei espartano. Com intenção de afastá-lo do poder, Cleomenes, outro rei espartano, suscita o questionamento sobre essa legitimidade e suborna o oráculo para que Pítia responda que Demáratos não era filho de Aríston:

Essa ideia de recorrer à Pítia fora premeditada por Cleomenes; este, então, obteve para a sua causa o apoio de Côbon, filho de Aristôfantos, personagem muito influente em Delfos, e Côbon persuadiu a sacerdotisa Períala a dizer o que Cleomenes queria que fosse dito; assim, interrogada pelos mensageiros a Pítia, declarou que Demáratos não era filho de Aríston. Essa intriga foi descoberta depois de algum tempo; Côbon teve de fugir de Delfos e a sacerdotisa Períala foi destituída de suas honrosas funções. (Hdt. VI.66)

A partir de ambos os episódios de subornos em relação à figura da sacerdotisa, Carrilho aponta que Pítia não estava salvaguardada dos avanços masculinos e que, enquanto mulher, estava sujeita às fragilidades do caráter humano; logo, o discurso de Heródoto não seria desprovido de controvérsia em relação à figura da mulher (2013, p. 74). Apesar de compactuarmos que há no discurso herodotiano a controvérsia ao discorrer sobre o feminino, vide as passagens citadas de Artemisa, discordamos de Carrilho. Não vemos a posição e a imagem de Pítia sendo questionada ou julgada por Heródoto e, além disso, quem foi destituída do posto de sacerdotisa foi Períala, que estava envolvida com Côbon, e não Pítia. A partir da análise do trecho e de diferentes traduções, Períala e Pítia não parecem ser a mesma pessoa. Adiciona-se que, neste caso, 
Mare Nostrum, ano 2020, v. 11, n. 1 .

nenhum adjetivo a respeito da figura da mulher a fim de rebaixá-la é mencionado por Heródoto.

No que concerne aos conselhos que Pítia profere, Dewald faz duas afirmações: primeiro que a profetisa, tal como seus conselhos, representa a intersecção da moral e da política para aqueles que a consultam; ela ajuda a resolver conflitos e corrige comportamentos, agindo sempre para o bem da pólis. Entretanto, segundo a autora, aos olhos de Heródoto, os conselhos não são dela, mas de Apolo. Ela seria apenas uma intermediária do deus. Dessa maneira, neste caso, a autora considera que a mulher seria mais uma mulher passiva na esfera de conflitos bélicos e representaria os limites do que é considerado humano e o que seria da ordem do divino-o futuro, por exemplo. Para além das considerações da historiadora, acreditamos que a intersecção do deus com a mulher não deixa de representar um lugar de poder ocupado pelas mulheres na Antiguidade e mais uma maneira que Heródoto mostra a mulher como responsável por manter a ordem política e social.

O supracitado Flower expõe que suposições de muitos historiadores versavam sobre se os oráculos entregues por Pítia eram inteligíveis, se suas palavras foram ordenadas por sacerdotes ou versificadores profissionais ${ }^{12}$. Assim como o autor, acreditamos que esses argumentos tinham como objetivo desprivilegiar a posição ocupada por uma mulher e eram questões relacionadas à mulher da época dos historiadores que estudaram os casos da Pítia e não do período de Heródoto. Ademais, rejeitavam o testemunho explícito que Heródoto transmitiu das falas do oráculo de Delfos da Grécia arcaica e clássica. Pressupor a existência de um sacerdote auxiliando Pítia e versificando suas palavras é alterar o que Heródoto nos diz, já que, em nenhum momento, o autor evidencia a presença de um homem assistindo à sacerdotisa.

\section{Considerações finais}

Após a exposição do debate historiográfico sobre a falta da obra de Heródoto na discussão de gênero na Grécia Antiga e análise de algumas passagens da atuação de Pítia em Histórias, o presente artigo teve como objetivo mostrar a relevância de

12 Para mais detalhes do debate ver, por exemplo, Parke e Wormell (1956); Crahay (1956); e Fontenrose (1978). 
Heródoto para uma análise da posição da mulher mais relacional na sociedade do século V a.C. na Grécia, considerando sua representação e influência no poder como algo que Heródoto nos mostra como pertencente àquela sociedade. Tentamos mostrar uma compreensão menos sistematizada, contrastando com a historiografia contemporânea que permanece analisando a ambiguidade da mulher a partir do mito de Pandora, em que o feminino e o masculino contrapõem-se. Acreditamos, através dos exemplos de Heródoto, que, na verdade, eles complementam-se para manter a ordem política e social da pólis.

O feminino parece ser adjetivado por Heródoto para além de Pandora e sa concepção de mélissa, de esposa silenciosa e obediente. Tanto com Artemísa, Gorgo, e Pítia, vemos a mulher agindo em prol do bem da pólis e aconselhando seu marido ou personagens masculinos. Permanecemos, assim, com a questão inicial, ainda sem resposta e mais indagadora quando analisamos as tantas descrições de Heródoto das relações entre o feminino e o masculino para narrar a organização da sociedade grega do século V a.C. nos entraves das Guerras Greco-Pérsicas: por que a historiografia permanece não utilizando Heródoto para analisar a sociedade grega pela perspectiva de gênero?

Recebido em 04.02.2020, aprovado em 23.03.2020. 
Mare Nostrum, ano 2020, v. 11, n. 1 .

\section{REFERÊNCIAS BIBLIOGRÁFICAS}

Fontes:

Heródoto. (1988). Histórias. (M. G. Kury, trad., introd. e notas) (2a ed). Editora Universidade de Brasília.

Heródoto. (2015). Histórias. (M. A. O. Silva, trad., introd. e notas). EDIPRO.

Heródoto. (1920). In Godley, A. D. (trad.) Herodotus: The Histories. Harvard University Press.

Estudos:

Amaral, A. L. (1994). Duas Rainhas em Heródoto: Tómiris e Artemísia. Humanitas, v. 46.

Andrade, M. M. (2001). “A cidade das mulheres": cidadania e alteridade feminina na Atenas Clássica. LHIA.

Andrade, M.M. (2003). Atenas uma cidade para as mulheres. LHIA.

Aniceto, B. A. (2017). As relações de gênero em Aristófanes: um estudo das esposas legítimas na sociedade ateniense (Sécs. V-IV $a C$ ). [Dissertação de Mestrado, UNESP].

Block, J. (2002). Women in Herodotus Histories. In Egbert, J., Bakker, I. J. F. J., \& Hans van Wees B,1 (eds). Companion to Herodotus (225-242). Brill.

Carrilho, S. M. M. (2013). Representações do Feminino nas histórias de Heródoto. [Dissertação de Mestrado, Universidade de Coimbra].

Dewald, C. (1981). Women and culture in Herodotus' Histories. Women's Studies: An Interdisciplinary Journal 8 (1-2), 93-127.

Dominick, Y. H. (Dec., 2007). Atossa and Instability in Herodotus. The Classical Quarterly, New Series, 57 (2), 432-444.

Goodwater, L. (1975). Women in antiquity: an annotated bibliography. Scarecrow Press. 
Flower, M. (2008). The seer in ancient Greece. University of California Press.

Hartog, F. (2014). O espelho de Heródoto: ensaio sobre a representação do outro. Editora UFMG.

Junqueira, N. J. (2011). Imagens da Mulher Grega: Heródoto e as pinturas em contrate. [Tese de doutorado, Universidade Estadual Paulista].

Kuhrt, A. (2001). Women and War. Journal of Gender Studies in Antiquity, 2, 1-27.

Loraux, N. (1997). The experiences of Tiresias - The feminine and the greek man. Princeton University Press.

Mitchell, L. (2019). Women in war and peace in Archaic and Classical Greece. Lecture. Museu de Arqueologia e Etnologia da Universidade de São Paulo.

Mitchell, L. (2020). Peace, War and Gender. In:AGER, S. (ed.). A Cultural History of Peace. Bloomsbury.

Mosse, C. (1990). La mujer en la Grecia clássica. NEREA.

Munson, R.V. (Apr., 1988). Artemisia in Herodotus. Classical Antiquity, 7 (1), 91-106.

Parke, H. W. \& Wormell, D. E. W. (1956). The Delphic Oracle: (Vol. 1). The History. Blackwell.

Pomeroy, S. B. (1973). Selected Bibliography on women in Antiquity. Arethusa. 6, (1), Women In Antiquity, 127-157. 
Mare Nostrum, ano 2020, v. 11, n. 1 .

\title{
Representation And Power: The Woman Who Spoke Through Apollo In Herodotus' Histories
}

\author{
Isabela Casellato Torres
}

ABSTRACT

The Histories, written in the fifth century $\mathrm{BCE}$ by Herodotus of Halicarnassus is the only work of the so-called "Father of History" that has reached the contemporary times. The author lived between $c .480-425$ BCE. In Histories, he addressed much more than the Graeco-Persian Wars, whose reports are the most substantial throughout history. In this context, Herodotus described the actions of Greek and Persian women as war advisers for their husbands and / or other male characters. According to his text, we argue that the Greek author believed that Greek and Persian women were equal in their performance: maintainers of the socio-political order. We analyze how the current scholarship has understood the feminine in Herodotus' work, based on the seer Pitia case study.

KEYWORDS

Gender history; War; Herodotus. 